\title{
Impact of highway on vertebrate roadkill in Nam Nao National Park, Thailand
}

\author{
WUTTISAK KUMMOO ${ }^{1}$, JIRAPORN TEAMPANPONG ${ }^{2, \boldsymbol{v}}$, PANTIYA UTSA ${ }^{2}$, PAANWARIS PAANSRI ${ }^{1}$, \\ WARONG SUKSAVATE ${ }^{1}$, PRATEEP DUENGKAE ${ }^{1}$, SUTIN PROMPAT ${ }^{3}$ \\ ${ }^{1}$ Department of Forest Biology, Faculty of Forestry, Kasetsart University. 50 Ngamwongwan Rd., Chatuchak, Bangkok 10900, Thailand. \\ Tel.: +66-2-579-0176, Fax.: +66-2-942-8107 \\ ${ }^{2}$ Department of Conservation, Faculty of Forestry, Kasetsart University. 50 Ngamwongwan Rd., Chatuchak, Bangkok 10900, Bangkok, Thailand. \\ Tel.: +66-2-579-0170, vemail: jiraporn.tea@ku.th \\ ${ }^{3}$ Department of National Parks, Wildlife and Plant Conservation, Nam Nao Nation Park. Nam Nao District, Phetchabun 67260, Thailand
}

Manuscript received: 5 October 2020. Revision accepted: 31 October 2020.

\begin{abstract}
Kummoo W, Teampanpong J, Paansri P, Suksavate W, Utsa P, Duengkae P, Prompat S. 2020. Impact of highway on vertebrate roadkill in Nam Nao National Park, Thailand. Biodiversitas 21: 5540-5549. Roads lead to biodiversity loss, primarily through wildlife collisions. This phenomenon is widespread, despite limited attention in Thailand. To reduce road mortality, the roadkilled species and their distributions along the road become a significant component for designing management strategies. We surveyed vertebrate mortality covering 44 kilometers of Highway 12, passing through Nam Nao Nation Park in Phetchabun Province of Thailand for 34 replicates between August 2018 and July 2019. We recorded 1,389 carcasses of 578 amphibians, 540 reptiles, 190 mammals and 81 birds. The rate of wildlife-vehicle collisions (WVCs) was $1.089 \pm 0.823$ carcasses $-\mathrm{km}^{-1} \mathrm{day}^{-1}$, comprised mostly of amphibians. The distribution pattern of WVCs was arranged in spatial clusters. Five wildlife collision hotspots for four taxa groups were identified. Overall, the WVC presence was positively associated with vegetation types but negatively associated with distance to the forest edge, the presence of road barriers and the number of road lane. Concurrently, the numbers of roadkill incidents were positively associated with amphibians more than other vertebrate groups, the night time and number of daily vehicles. Our results suggest that WVC rates on HW12 vary among taxonomic groups, temporal scales and environmental factors. It highlights key hotspots where mitigation strategies should be implemented for biodiversity conservation.
\end{abstract}

Keywords: Nam Nao National Park, roadkill, Thailand, wildlife-vehicle collisions

Abbreviations: CR: Critically endangered; HW 12: Highway 12; NNNP: Nam Nao National Park; WVCs: wildlife-vehicle collisions

\section{INTRODUCTION}

Roads have been associated with human settlements since historical time to facilitate the movement of goods and travel of people around the world (Forman et al. 2003; Coffin 2007; Liu et al. 2013; van der Ree et al. 2015). Therefore, roads play a role in stimulating economic growth and development of the regions (Laurance 2015). In contrast, roads are also known as one of the most critical threats to species existence (Forman et al. 2003; Coffin 2007; van der Ree et al. 2011).

The most noticeable impact of roads and traffic is the wildlife-vehicle collision (hereafter WVC). It leads to the mortality or injuries of both humans and wildlife, directly affects human safety and wildlife populations (Hels and Buchwald 2001; Malo et al. 2004; Plante et al. 2019) and wildlife conservation (Gunson and Teixeira 2015). For example, vehicle collision with large mammals causes nearly 30,000 injuries and 200 deaths of humans per year (Conover et al. 1995). It also indirectly affects changing wildlife behavior (Andrews et al. 2008). The other impacts of WVC include habitat loss and degradation through edge effects and gap creation by roads and road pollution such as noise and light that limit wildlife movement and become a barrier impeding population survival, gene flow and population persistence. Roads also drive the species to either avoid the surrounding area of traffic congestion, or they are attracted to roads (van der Ree et al. 2015). For example, reptiles use the road to control body temperature. Herbivores get close to the road to search for food plants along the roadside. Predators and scavengers also eat carcasses killed by vehicle collisions (Meunier et al. 2000; Barthelmess et al. 2010). Illegal logging, hunting and forest fires often occur near roads, especially the roads passing through large contiguous forest patches with high biodiversity (Laurance 2015). Moreover, the effects of roads are long-lasting from the time of their construction and continue as long as they are still in use, eventually causing severe risks for wildlife extinction in the future (Forman et al. 2003).

WVC causes more severe injuries or death from accidents in the northern hemisphere than the tropics. Nevertheless, the diversity of species hit by vehicles was higher in the tropics (Farmer and Brooks 2012). Hence, roads in tropics are more relevant to conservation than safety, especially in protected areas (Forman et al. 2003; Freitas et al. 2013). Factors affecting WVCs such as traffic variability (Fahrig et al. 1995), temperature and precipitation also influence road mortality risk, frequency or prevalence 
(Shepard et al. 2008). In wetter environments, paved roads provide year-round access to natural resources and are typically more extensive and have faster-moving traffic than unpaved roads. They are thereby a greater danger and movement barrier to wildlife (Laurance 2015). Therefore, the roads in protected areas can diminish biodiversity.

While road impacts are globally recognized, conservationists cannot compete with the view that road expansion can speed up economic growth and social harmonization (Alamgir et al. 2017). Nam Nao National Park (hereafter NNNP) is part of the Phu Khieo-Nam Nao Forest Complex in northeastern Thailand, the sixth-largest contiguous protected area of Thailand covering an area of more than 7,000 $\mathrm{km}^{2}$ (Lynam et al. 2001). NNNP supports a range of IUCN red-listed wildlife (IUCN 2020) including the critically endangered Elongated Tortoise (Indotestudo elongata), endangered Asian elephant (Elephas maximus), Indochinese Tiger (Panthera tigris) and Big-headed Turtle (Platysternon megacephalum). Unfortunately, NNNP has faced this challenge since the construction of Highway 12 (hereafter HW 12) 60 years ago (Tongthiangdee 2003). Therefore, it is a risk factor for losing wildlife habitats, changing wildlife population dynamics and biodiversity from the expansion of HW 12 from two to four lanes under the project of the Upper East-West Economic Corridor (Montague 2009). A lack of field-researched data of species affected by roads for designing alternatives of effective road management is more urgent to NNNP than the data on losses of humans and wildlife from the collision, both economic costs, and biodiversity loss even though most western countries began the studies on road impacts and traffic from the reduction of large-scale wildlife collisions, human losses and the economic cost of vehicle collisions (Legagneux and Ducatez 2013).

This research, therefore, aims to evaluate the differences in vertebrate roadkills in NNNP according to the seasons, months and time of day (morning, afternoon). The study also identified the pattern of WVCs distribution and hotspots along HW 12, and determining factors driving the WVC occurrence and the numbers of roadkill incidents. The research results eventually guide the construction of ecological corridors or other measures to reduce the biological impacts of HW 12 on vertebrate roadkill.

\section{MATERIALS AND METHODS}

\section{Study area}

This study was conducted on 44 kilometers of HW 12 passing through NNNP $\left(16^{\circ} 44^{\prime} 0^{\prime \prime} \mathrm{N} 101^{\circ} 33^{\prime} 4^{\prime \prime} \mathrm{E}\right)$. Our study site was located between the 384 and 428 milestones and is under the supervision of section 603 of Phetchabun Highway District 1. The Head Quarter of NNNP lies in the middle of this road section. It is a two-lane winding mountain route located in an altitude from 400 to 950 meters above mean sea level (Office of National Parks 2017). Only some road curves were composed of the three-lane road. Traffic intensity was approximately 3,000 vehicles per day, with a two percent increase annually, and heavy trucks had a high rate of annual increase of nine percent (Department of Highways 2017). There are three main seasons in this region-the dry (February to April), rainy (May to October) and cold (November to January) seasons. The average annual temperature of NNNP is $25^{\circ} \mathrm{C}$ ranging from 18.2 to $35.5^{\circ} \mathrm{C}$ with an average annual precipitation of $1,038.3 \mathrm{~mm}$ (Office of National Parks 2017) (Figure 1).

\section{Data collection}

Two observers surveyed vertebrate carcasses on-road simultaneously in a moving motorcycle. Each observer kept track of carcasses on each road lane while driving at a constant rate of $30 \mathrm{~km} /$ hour, as suggested by Collinson et al. (2014). We surveyed between two to five successive days, with two surveys per day in early morning starting at 30 minutes after sunrise (Santos et al. 2011) and in the late afternoon starting roughly at $3.00 \mathrm{pm}$. We attempted to choose an equal interval between consecutive months from August 2018 to July 2019, resulting in 34 sampling days, separating to 30 samplings in the morning, and 27 samplings in the afternoon. The survey covered a total of 1,276 kilometers.

This study took only amphibians, reptiles, birds and mammals into account. Once detected, the carcasses were marked in the GPS unit system (Garmin 60 csx). Species were recorded to the most likely taxonomic category, counted and photographed. All carcasses were then removed from the road to prevent double-counting (Guinard et al. 2015). Concurrently, park rangers collected the total numbers of vehicles using the road between 384 and 428 milestones for 24 hours during sampling days.

We checked retention time of carcasses in good condition of five mammals, two birds, 38 reptiles and 46 amphibians. These carcasses were checked every hour to note their retention time from road removal. We also measured biophysical factors (Table 1) where the vertebrate roadkill was absent to understand factors influencing roadkills. To do so, we separated the road into 215 sections at 200-meter intervals and generated three random points at each section outside the 10-meter buffered roadkill incidents in ArcGIS 10.0 (ESRI 2011), resulting in a total of 645 random points.

\section{Data analysis}

We performed all statistical analysis in $\mathrm{R}$ software version 4.0.2 ( $\mathrm{R}$ Development Core Team 2020). We used descriptive statistics including mean $(\overline{\mathrm{x}})$, standard deviation (SD), and percentage to describe the number of carcasses of each species killed on-road and biophysical factors. The WVCs data were grouped into possible taxonomic groups of anurans (frogs and toads), caecilians, snakes (serpents), agamids, geckonids, scincids, varanids, turtles, birds, birds of prey, bats and small mammals to identify group taxa most at risk of road mortality. In the case that the sample sizes of some groups were large enough, we grouped them into more specific taxonomic ranks. 


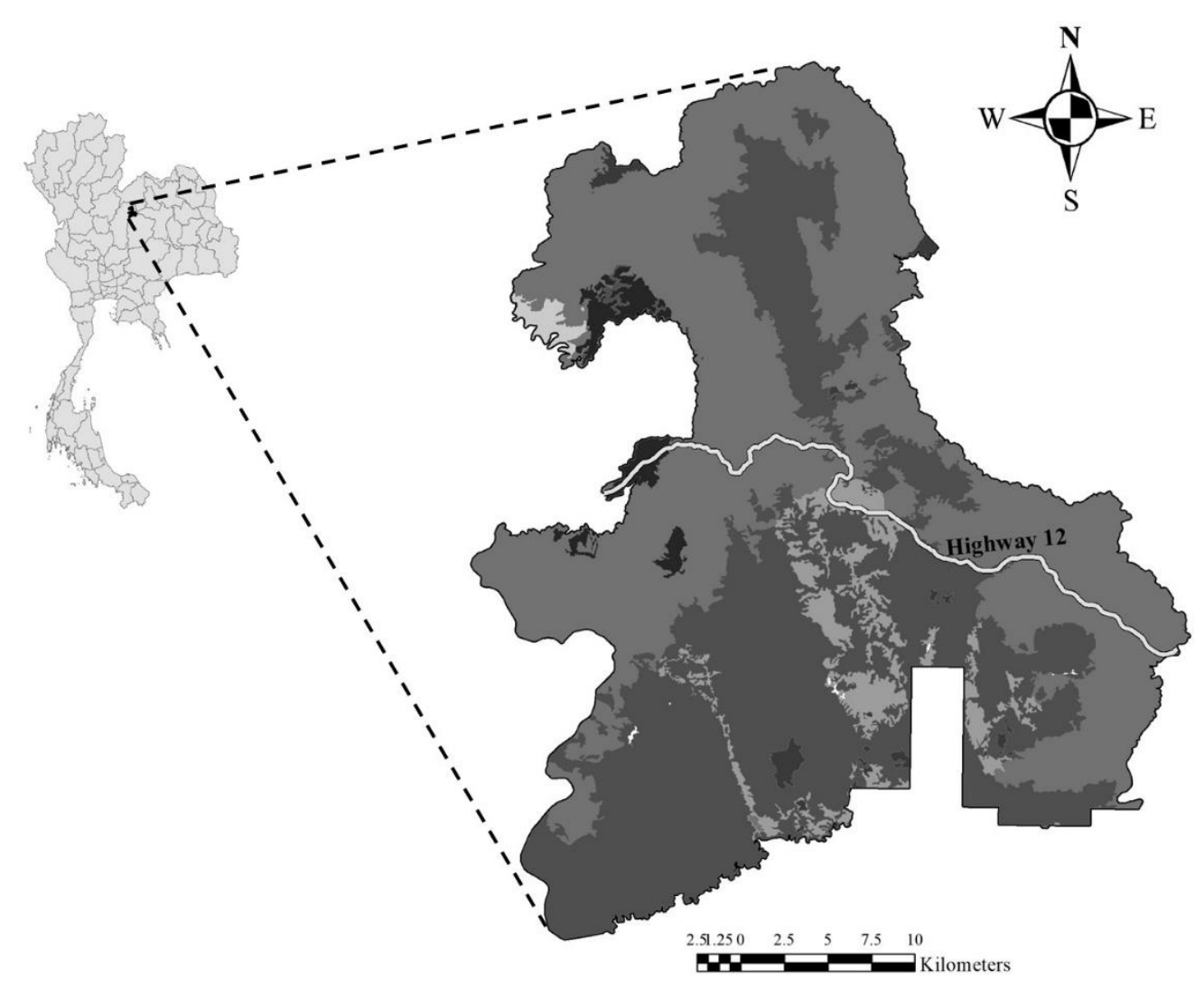

Figure 1. Location of Highway 12 in Nam Nao National Park, Phetchabun Province, Thailand

Table 1. Variables used to identify factors influencing roadkill incidence with a generalized linear model (GLM)

\begin{tabular}{ll}
\hline \multicolumn{1}{c}{ Definition } & \multicolumn{1}{c}{ Unit (type) } \\
\hline Height above mean sea level & meters (continuous) \\
Distance to the nearest forest edge of the inbound road & meters (continuous) \\
Distance to the nearest forest edge of the outbound road & meters (continuous) \\
Distance to the nearest stream & meters (continuous) \\
Distance to nearest the tourist sites & meters (continuous) \\
Distance to the nearest ranger stations & meters (continuous) \\
Slope form at a specific point & \% (continuous) \\
Road characteristics at WVC locations & Straight, Curve (categorical) \\
Road topography at WVC locations & flat, hilly, cliff (categorical) \\
Number of road lane & 2-lane and 3-lane (categorical) \\
Presence of cement roadblock & Presence and absence (categorical) \\
Dominant vegetation & Dry evergreen, mixed deciduous, pine, dry dipterocarp and ecotone (categorical) \\
Vertebrate groups & Amphibians, reptiles, birds, mammals (categorical) \\
Time of day & Day/night (categorical) \\
Numbers of vehicles & Numbers (continuous) \\
\hline
\end{tabular}

We calculated the WVC rate by dividing the total number carcasses found at each road section of a kilometer per day, as suggested by Garrah et al. (2015), so its unit was reported as the number of carcasses- $\mathrm{km}^{-1} \mathrm{day}^{-1}$. The overall WVC rate was assessed monthly. We then compared and tested the WVC rate of different taxa between rainy, dry and cold seasons, among the months using the Kruskal-Wallis Test and between day and night times using the Mann Whitney U Test.
We used the Nearest Neighbor Analysis (NNa) to examine the distribution patterns with the GmAmisc package in $\mathrm{R}$ (Alberti 2020). NNa explained the spatial aggregation of WVCs by testing whether the pattern was clustered, dispersed or random. This function uses a randomized approach to test the significance of the ClarkEvans R statistic. The observed R-value is set against the distribution of $\mathrm{R}$ values computed across 199 iterations by default. A set of random points equally generated to the 
number of points of the input feature was drawn, and the statistic was recomputed. The function produced a histogram of the randomized R-values. The pattern of distribution was determined based on the R-value of which its value referred to a cluster $(\mathrm{R}<1)$, random $(\mathrm{R}=1)$, or dispersed $(\mathrm{R}>1)$.

We determined significant clusters of high mortality for each taxon by accumulating data by month. The analysis was conducted for road segments of 100, 200, 500, and 1,000 m using the Getis-OrdGi* statistic (Garrah et al. 2015) in ArcGIS 10.0 (ESRI 2011). Road segments considered as road mortality hotspots were identified when the GetisOrdGi* statistic returned a $\mathrm{z}$ score $\geq 1.96$.

Finally, we used generalized linear models (GLMs) with a binomial distribution and a logit link function to identify factors influencing overall roadkill incidents along HW 12. We additionally ran point-based GLMs with Poisson distribution and log link function to understand the association between daily roadkill incidents and vertebrate groups, time of the survey (morning or afternoon) and the numbers of vehicles during our sampling days. The MASS package and Akaike's information criterion were used to evaluate the best model fit (Venables and Ripley. 2002). The factors using in the models were shown in Table 1.

\section{RESULTS AND DISCUSSION}

We found 1,389 mortalities of 86 species in 67 genera ( $57.73 \%$ identified to genus) in 40 families of four classes on HW 12. This number included 578 amphibians, 540 reptiles, 190 mammals 81 birds and two domestic cats. We excluded the domestic cat from the analysis because it was not of our interest. The 86 species were classified to 12 species in 11 genera in six families of amphibians, 41 species in 28 genera in 10 families of reptiles, 28 species in 23 genera in 17 families of birds and six species in six genera in five families of mammals. The list of roadkilled species was shown in the table of supporting information.

Most of the roadkilled amphibians were anurans (frogs and toads: $98.79 \%)$ and caecilians $(1.21 \%)$. Snakes (serpents) shared the largest proportion of roadkilled reptiles $(53.52 \%)$, followed by agamids $(36.67 \%)$, geckonids $(6.11$ $\%)$, scincids $(2.41 \%)$, varanids $(1.11 \%)$ and turtles $(0.19$ $\%)$. Most roadkilled birds were resident except the Bluewinged Pitta (Pitta moluccensis), a passage migrant. Understory birds were killed in a higher proportion than $(35.71 \%)$ nocturnal birds $(23.81 \%)$, mid-storied birds $(23.81 \%)$ and birds of prey $(4.76 \%)$. Rodentia $(57.22 \%)$ shared the largest proportion of roadkilled mammals, followed by bats (38.50\%), squirrels (3.21\%), a bamboo rat $(0.53 \%)$ and a leopard cat $(0.53 \%)$.

The WVC rate of all vertebrates was $1.089 \pm 0.823$ carcasses-km-1day-1. Amphibians had the highest WVC rate at $0.453 \pm 0.317$, followed by reptiles $(0.423 \pm 0.071)$, mammals $(0.149 \pm 0.064)$ and birds $(0.063 \pm 0.046)$, respectively. From this number, frogs and toads were disproportionately killed on the road more than caecilians. Snakes were roadkilled in a higher proportion than agamids, geckonids, scincids, varanids and turtles. Rodentia were hit on roads more often than small-sized bats, mostly insectivorous bats. This mortality rate could be underestimated for several reasons. We observed that the carcasses were scavenged by crows and Accipiter spp., and were in a state of disintegration, decomposition and removal due to vehicles running over them. Average carcass retention time on the road was $18.91 \pm 15.33$ hours.

Most of the species hit on HW 12 were globally of least concern (LC). Only the King Cobra (Ophiophagus hannah) and the Burmese Python (Python bivittatus) were considered globally vulnerable (VU), and the Spiny Turtle (Heosemys spinosa) was globally endangered (EN). A Leopard Cat (Prionailurus bengalensis) was the only medium-sized mammal killed once on HW 12. We found Asian Elephants crossing the road at many locations, especially between the milestones of 408 and 412 during the study. Park rangers also reported elephant injury and the death of sambar deer and wild boar due to WVC at night time.

\section{Temporal order of wildlife-vehicle collisions by seasons, months and day-night}

We surveyed the WVC in dry, rainy, and cold seasons for 352, 616, and 286 kilometers, respectively. The WVC rate was highest in the rainy season $(1.321 \pm 0.218$ carcasses $\left.-\mathrm{km}^{-1} \mathrm{day}^{-1}\right)$, followed by the dry $(1.283 \pm 0.253)$ and cold $(0.675 \pm 0.116)$ seasons. The highest WVC rates of reptiles and mammals were in the rainy season and of the amphibians and birds were in the dry and cold seasons, respectively. The estimated WVC rates did not significantly differ among seasons except for birds $(\mathrm{df}=2, p=0.042)$, especially in the rainy and cold seasons $(p=0.026)$ (Figure 2.A).

An average of $106.3 \pm 48.2$ kilometers was surveyed per month. The distribution of WVC incidents was not homogenous all year round. The highest and lowest WVC rate was in September $(2.30 \pm 0.401)$ and January $(0.386 \pm$ 0.144 carcasses $\left.-\mathrm{km}^{-1} \mathrm{day}^{-1}\right)$, respectively. The monthly WVC rates of each taxon group were not significantly different ( $p$ $=0.44$ ) (Figure 2.C).

Finally, the 594 and 682 kilometers were surveyed to explore roadkill incidences occurring during the day and night time, respectively. More than $70 \%$ of all taxa were hit at night with an average of $1.412 \pm 0.823$ carcasses $-\mathrm{km}^{-1}$ day ${ }^{1}$, higher than the day time $\left(0.657 \pm 0.833\right.$ carcasses- $\mathrm{km}^{-1} \mathrm{day}^{-}$ $\left.{ }^{1}\right)$. Amphibians had the highest WVC rate at night, followed by reptiles, mammals and birds in decreasing order. In contrast, reptiles had the highest WVC rate during the day, followed by amphibians, mammals and birds, respectively. The WVC rate was not significantly different between day and night time, except for mammals $(P=0.006)$ (Figure 2.B).

\section{Spatial distribution of wildlife-vehicle collisions on $\mathrm{HW}$ 12 in NNNP}

The results from the Nearest Neighbor Analysis (NNa) showed that the frequency of WVC rate in each road section of all taxon groups were significantly different. Accordingly, the $\mathrm{NNa}$ indicated that all taxon groups exhibited a clustered pattern of distribution on HW 12 in NNNP $(p<0.01)$ with the R-values for amphibians at 0.143 , for reptiles at 0.166 , for mammals at 0.270 and birds at 0.436 . 


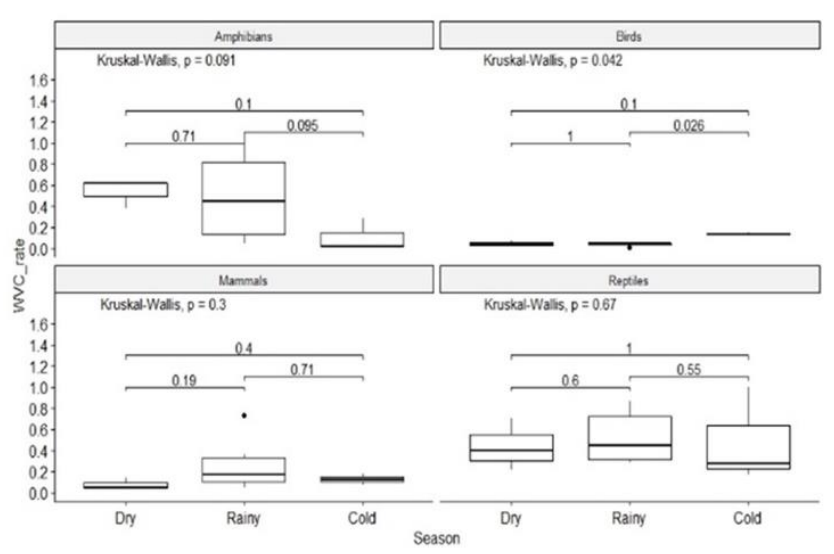

A

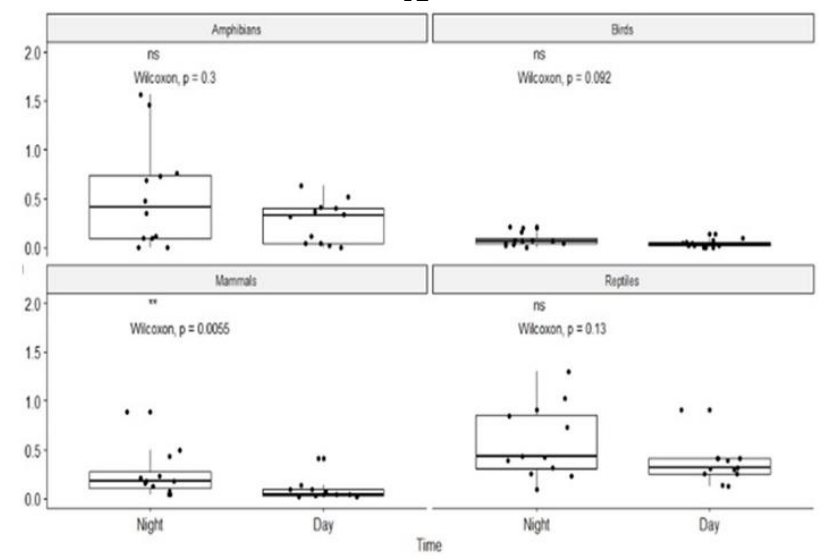

B

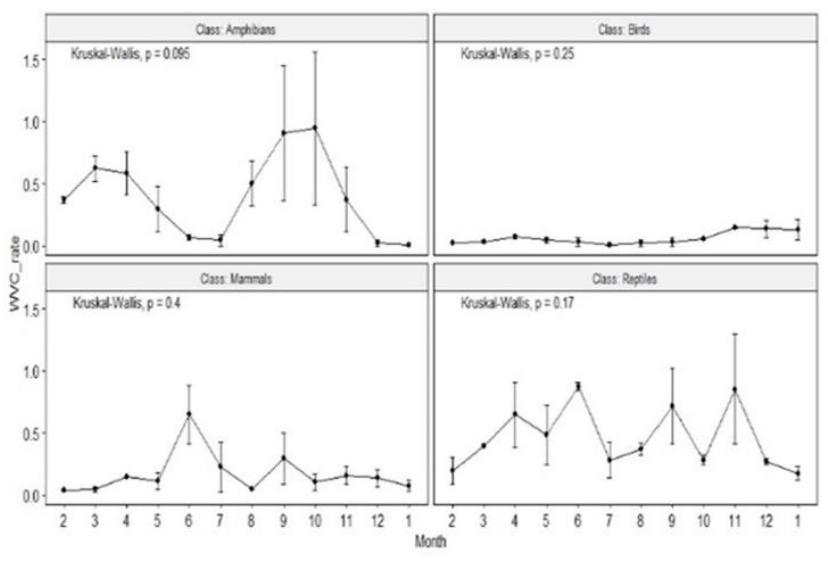

C

Figure 2. The different wildlife-vehicle collision rates among seasons (A), between day and night times (B), and months (C) comparing by taxonomic groups. The Kruskal-Wallis and Wilcoxon tests were used. The WVC rates are reported in a unit of carcass- $\mathrm{km}^{1}$-day ${ }^{1}$. The numbers of $1-12$, represent the months of January through December. The numbers on graphs represent the p-value of a comparison.

\section{Hotspots of wildlife-vehicle collisions on HW 12}

The Getis-Ord analysis indicated that the optimal balance of scale for hotspot analysis was better at $200 \mathrm{~m}$ segments than the 100,500 , and $1,000 \mathrm{~m}$. The distribution of WVC hotspots across the study area for all and for each taxonomic group was clumped. Five hotspots for all vertebrate groups were identified at the road section at the milestone of 388.8, 397.6, 424.4, 425.2, and 426.0. None of them overlapped with the hotspots for particular taxonomic groups. We found hotspots for amphibians at 423.2, 424.2, and 425.8 and for reptiles at 388.0, 389.0, and 393.2. The hotspots of bird mortality did not overlap with hotspots of other taxonomic groups and were located at the milestones of 404.0 and 405.2. Finally, the hotspots of mammals were located at the milestones of 390.4, 391.2, 392.0, 392.8, 394.0, 395.2, and 397.0 as shown in Figure 3.

\section{Driving factors of wildlife-vehicle collision on HW 12}

Our best-supported model indicated that the probability of WVCs significantly occurs in a mixed deciduous forest over the dry dipterocarp forest $(P<0.01)$. Moreover, WVCs tended to be significantly higher for the locations on roads with a shorter distance from the road to the forest edge, with no cement roadblocks and on two-lane roads (Table 2).

Furthermore, our best-supported model for each taxon explained that the numbers of roadkill incidents of reptiles, birds and mammals were $0.244,2.621$, and 1.249 times lower than amphibians, respectively. Nighttime and the more numbers of vehicles exhibited a strong positive relationship for the numbers of roadkill incidence (Table 3).

Table 2. Coefficients, standard errors, and significance levels of the logistic regression model fitted to the observations of 200-m posts with and without wildlife-vehicle collisions

\begin{tabular}{llll}
\hline \multicolumn{1}{c}{ Parameters } & $\begin{array}{c}\text { Coeffici } \\
\text { ent }\end{array}$ & SE & \multicolumn{1}{c}{$\boldsymbol{P}$} \\
\hline (Intercept) & 3.095 & 0.587 & $1.34 \times 10^{-7}$ \\
Elevation & -0.001 & 0.0004 & 0.073 \\
Road topography: ref-cliff & & & \\
$\quad$ Hilly & -0.236 & 0.1745 & 0.176 \\
$\quad$ Flat & 0.263 & 0.217 & 0.226 \\
Vegetation: ref-dry dipterocarp forest & & & \\
$\quad$ Dry evergreen forest & -0.513 & 0.322 & 0.111 \\
$\quad$ Ecotone & -1.492 & 0.262 & 0.569 \\
$\quad$ Mixed deciduous forest & 0.944 & 0.223 & $2.31 \times 10^{-5}$ \\
$\quad$ Pine forest & 0.044 & 0.273 & 0.871 \\
$\begin{array}{l}\text { Distance from the forest edge to the } \\
\text { inbound road }\end{array}$ & -0.225 & 0.046 & \\
Distance from the forest edge to the & -0.252 & 0.064 & \\
outbound road & -0.679 & 0.197 & $5.06 \times 10^{-5}$ \\
No. of road lane & -1.644 & 0.194 & $<2 \times 10^{-4}$ \\
Road barrier & & &
\end{tabular}

Note: AIC $=1818.6$, residual deviance 1794.6, $\mathrm{df}=1446$, no. of fisher scoring iterations $=4$

Table 3. Coefficients, standard errors and significance levels of the generalized linear model fitted to the numbers of roadkill incidence

\begin{tabular}{lllc}
\hline \multicolumn{1}{c}{ Parameters } & Coefficient & \multicolumn{1}{c}{ SE } & P \\
\hline Intercept & 1.826 & $1.198 \times 10-1$ & $<2 \times 10-16$ \\
Vertebrate group: & & & \\
Amphibian as a reference & & & \\
$\quad$ Reptiles & -0.244 & $6.879 \times 10-2$ & 0.000398 \\
$\quad$ Birds & -2.621 & $1.751 \times 10-1$ & $<2 \times 10-16$ \\
$\quad$ Mammals & -1.249 & $9.657 \times 10-2$ & $<2 \times 10-16$ \\
Time of day: & & & \\
Day time as a reference & & & \\
$\quad$ Night time & 1.734 & $1.030 \times 10-1$ & $<2 \times 10-16$ \\
No. of all vehicles & $1.090 \times 10-4$ & $9.838 \times 10-6$ & $<2 \times 10-16$ \\
\hline $\begin{array}{l}\text { Note: AIC }=758.26, \text { residual deviance } 509.89, \mathrm{df}=58, \text { no. of fisher } \\
\text { scoring iterations = 5 }\end{array}$ & & &
\end{tabular}




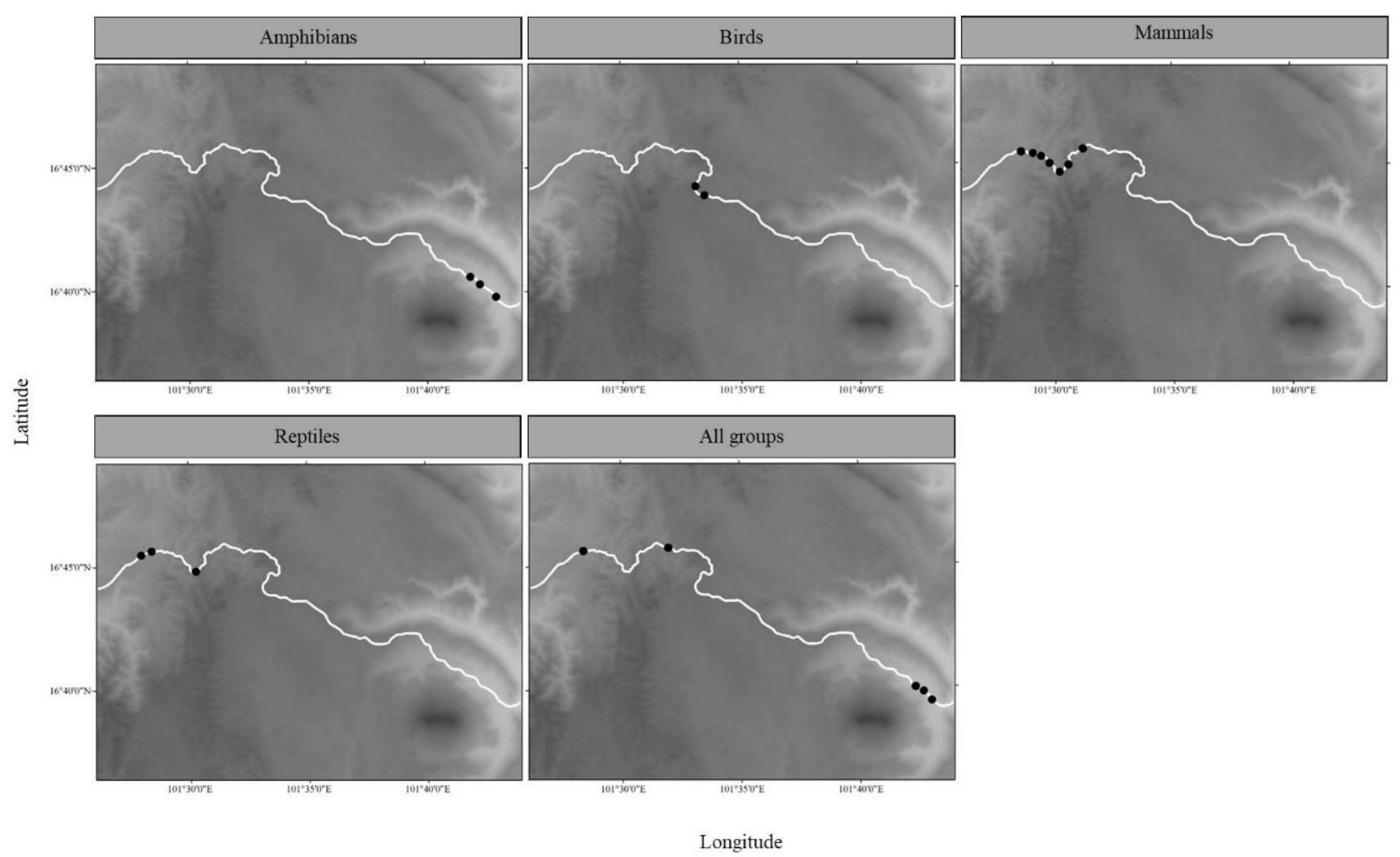

Figure 3. Wildlife-vehicle collision hotspots at a local scale of a 200-m radius of all and each vertebrate group

\section{Discussion}

Our study over 12 months from August 2018 through July 2019 for 34 days collected 1,391 roadkilled individuals along the 1,275 kilometers of the 44-km road in NNNP. We believe this number is underestimated due to our witnessing scavengers and birds of prey feeding on carcasses, as also reported by Zhang et al. (2018). We also observed carcass disintegration and removal from the road due to high traffic volume and vehicle speed, as confirmed by Hobday (2010).

\section{Taxonomic composition of wildlife-vehicle collisions on HW 12}

Our study found amphibians are the most vulnerable to roadkill, accounting for $41.55 \%$ of all individuals and 13.95 $\%$ of all detected species. This result was in line with a study in India by Jeganathan et al. (2018) and in China by Wang et al. (2013) that frogs constitute a higher proportion of roadkill than caecilians.

The reason that amphibians shared the highest proportion of roadkill in NNNP could relate to their life history. Amphibians rely more on aquatic habitats, therefore, fluctuation of water levels may drive their movement between breeding and feeding sites across the roads (Smith et al. 2005). Even though the distance to streams did not influence the presence of roadkill incidents in our study, we found temporary streams and water bodies and drainage along HW 12 and might influence amphibians being roadkilled in the highest proportion among taxonomic groups. As a result, amphibians were more sensitive to the fragmented habitats from roads for the long-term persistence of metapopulations (Marsh et al. 2008; Hamer et al. 2015).

The mortality rate of reptiles from roadkill was the second-highest in NNNP, especially snakes, therefore, similar to Jeganathan et al. (2018). Nevertheless, some other studies in Asia found that reptiles were the most vulnerable taxon among vertebrate groups (Suwanwaree and Aroon 2014; Hastings et al. 2019; Silva et al. 2019). The mortality rate of reptiles in NNNP was high at night and in the rainy season. It was possibly due to thermoregulation that allows slow movement behaviors of reptiles (Baskaran and Boominathan 2010) when the temperature dropped down at night and in the rainy season.

Understory-bird species were the most susceptible to roadkill on HW 12. We observed they were sitting and foraging on roads or crossing the road at a low height near the forest edge, similar to the findings by Husby (2017). Birds were hit in the cold season significantly more often than the rainy season, therefore differed from many studies where bird mortality was higher in summer than other taxonomic groups (da Rosa and Bager 2012; Collinson et al. 2014). We are convinced that decreasing available food in the cold season could attract birds to forage for grain lost from passing vehicles (Husby 2017), food waste from road users, or insects on roads, so the bird mortality was likely higher on HW 12 in the cold season than the other seasons.

Most mammals killed on HW 12 were bats and species in Order Rodentia. We observed only two medium-sized mammals killed on HW 12. The small number of medium- 
sized mammals killed on HW 12 could be due to their low density (Silva et al. 2019) along HW12. Evidence from camera traps on use of drainage culvert under the bridges of HW 12 by at least seven species of medium-sized mammals could be the other reason for the low WVC of medium-sized mammals on HW12. Insectivorous bats killed on the road could potentially be due to their small size, slow and low flight patterns, and forest-adapted species (Abbott et al. 2015).

While our study found mammals were frequently hit on HW 12 in the rainy season, albeit not significantly different from other seasons, Collinson et al. (2014) and Silva et al. (2019) found mammals were more likely to be hit in hot and cold seasons, respectively. We doubted the high WVC rate of mammals, mostly bats and Rodentia on HW 12 in rainy season could correlate to the time of dispersal of juveniles that happened a few months after parturition in the late hot season.

\section{Spatial patterns of wildlife-vehicle collisions and hotspots on $\mathrm{HW} 12$}

Our results explained spatial clusters of the wildlifevehicle collisions were similar to Silva et al. (2019). Our results suggest two locations where mitigation measures should be implemented to reduce road mortality of amphibians, reptiles and small- and medium-sized mammals. The two road sections were situated between the milestones 390 - 395 and 423 - 426 near watercourses. These two hotspots could be good for additional constructions to facilitate the movement of wildlife underneath the road such as drainage culverts or bridges. We found the use of drainage culverts and the space under the bridges near the two hotspots were frequented by the Radiate Rat Snake (Coelognathus radiata), House Rat (Rattus rattus), Asian Small-clawed Otter (Aonyx cinereus), Crabeating Mongoose (Herpestes urva) and Large Indian Civet (Viverra zibetha). Consequently, we recommended these locations for adding connectivity structures by modifying current drainage culverts and bridges by adding fences to facilitate the movement of amphibians, reptiles and some small mammals.

\section{Factors influencing wildlife-vehicle collisions on HW 12}

Our study exhibited a high WVC rate between mixed deciduous forests, similar to Selvan et al. (2012) who found a high percentage of roadkills on highways of Karnataka, India in mixed deciduous, teak and bamboo forests. Thus, vegetation made contributions toward explaining roadkill sightings (Yue et al. 2019) but may vary in different regions and landscape matrix where the road cut through. Our study found two-lane roads had a higher incidence of collisions with animals and were consistent with the findings from Hughes et al. (1996), especially the roads in forests and along rivers. The effect of the two-lane road was cleared when comparing our findings with Silva et al. (2019) who studied roadkill on HW 304 passing through Dong Prayayen Khao Yai Heritage Site. Our study found the average mortality rate on a two-lane road at 47.916 carcasses-day, ${ }^{-1}$ and it was higher than on HW 304 (15.8 carcasses-day $^{-1}$ ). However, Silva et al. (2019) found a slightly higher mortality rate on four-lane road sections than on two-lane road sections, albeit not significantly different. We would assume that NNNP could have a higher mortality rate of vertebrates if the HW 12 would be expanded to four-lane roads based on the findings from Silva et al. (2019).

The increasing numbers of vehicles and the nighttime played significant roles in the intensity of road mortality in our study. This result was in line with Zhang et al. (2018) who found a significant positive correlation between road mortality of amphibians and the average number of vehicles during the night.

\section{Conservation implications}

Road impacts appear localized and pose a significant threat to local populations of some susceptible species (Bennett 1992; Beckmann and Hilty 2010). This study suggests the following mitigation measures to reduce WVC in NNNP based on our results. A temporal traffic restraint at night during the rainy season could be applied to reduce WVC incidences. NNNP should adapt existing road structures to either prevent or facilitate wildlife crossings such as cement road barriers and drainage culverts. This finding also suggests appropriate locations for wildlife crossings on HW 12 if eventually the HW 12 road will be expanded from two to four lanes. We recommend further study to better understand other potential links to road impacts on HW 12 in NNNP based on our field experiences. The factors that should be taken into account for facilitating safety wildlife crossing include traffic noise, vehicle speed, use of drainage culverts, population density and species behavior.

\section{ACKNOWLEDGEMENTS}

We would like to thank the Department of National Parks, Wildlife, and Plant Conservation of Thailand for granting permission necessary to conduct this work. We also thank field assistance by the staff of Nam Nao National Park, Warut Chaleekarn, Jidapha Thongbanthum, Chattakan Ngamchaluay, Wipavee Hoonheang and Chanchai Ploysri.

\section{REFERENCES}

Abbott IM, Berthinussen A, Stone E, Boonman M, Melber M, Altringham J. 2015. Bats and roads. In: van der Ree R, Smith DJ, Grilo C (eds) Handbook of Road Ecology. Wiley-Blackwell, New York.

Alamgir M, Campbell MJ, Sloan S, Goosem M, Clements GR, Mahmoud MI, Laurance WF. 2017. Economic, socio-political, and environmental risks of road development in the tropics. Curr Biol 27 (20): 1130-1140.

Alberti G. 2020. GmAMisc: 'Gianmarco Alberti' Miscellaneous. R package version 1.1.1. https://cran.r-project.org/

Andrews KM, Gibbons JW, Jochimsen DM, Mitchell J. 2008. Ecological effects of roads on amphibians and reptiles: A literature review. Herpetol Conserv 3: 121-143.

Barthelmess EL, Brooks MS. 2010. The influence of body-size and diet on road-kill trends in mammals. Biodivers Conserv 19 (6): 1611-1629.

Baskaran N, Boominathan D. 2010. Roadkill of animals by highway traffic in the tropical forests of Mudumalai Tiger Reserve, southern India. J Threatened Taxa 2 (3): 753-759.

Beckmann JP, Hilty JA. 2010. Connecting wildlife populations in fractured landscapes. Safe passages: Highways, wildlife, and habitat connectivity. J Mammal 92 (5):1140-1141 
Bennett AF. 1992. Roads, roadsides and wildlife conservation: a review. .Nature conservation 2: The role of corridors. Biol Conserv 60 (1): 64.

Coffin AW. 2007. From roadkill to road ecology: a review of the ecological effects of roads. J Transport Geogr 15 (5): 396-406.

Collinson WJ, Parker DM, Bernard RT, Reilly BK, Davies-Mostert HT 2014. Wildlife road traffic accidents: A standardized protocol for counting flattened fauna. Ecol Evol 4 (15): 3060-3071.

Conover MR, Pitt WC, Kessler KK, DuBow TJ, Sanborn WA. 1995. Review of human injuries, illnesses, and economic losses caused by wildlife in the United States. Wildl Soc Bull 23 (3): 407-414.

da Rosa CA, Bager A. 2012. Seasonality and habitat types affect roadkill of neotropical birds. J Environ Manag 97: 1-5.

Department of Highways. 2012. Map showing the amount of traffic on the highway. http://bhs.doh.go.th/files/Map_aadt60/Div6/dist551.pdf

Environmental Systems Research Institute [ESRI]. 2011. ArcGIS Desktop: Release 10. Environmental Systems Research Institute, Redlands, CA

Fahrig L, Pedlar JH, Pope SE, Taylor PD, Wegner JF. 1995. Effect of road traffic on amphibian density. Biol Conserv 73 (3): 177-182.

Farmer RG, Brooks RJ. 2012. Integrated risk factors for vertebrate roadkill in southern Ontario. J Wildl Manag 76 (6): 1215-1224.

Forman RT, Sperling D, Bissonette JA, Clevenger AP, Cutshall CD, Dale VH, Fahrig L, Heanue K, France RL, Goldman CR, Jones J. 2003. Road Ecology: Science and Solutions. Island Press, Washington.

Freitas SR., Sousa CO, Bueno C. 2013. Effects of landscape characteristics on roadkill of mammals, birds and reptiles in a highway crossing the Atlantic Forest in southeastern Brazil. International Conference on Ecology and Transportation (ICOET 2013), Arizona.

Garrah E, Danby RK, Eberhardt E, Cunnington GM, Mitchell S. 2015. Hot spots and hot times: Wildlife road mortality in a regional conservation corridor. Environ Manag 56 (4): 874-889.

Guinard É, Prodon R, Barbraud C. 2015. Case study: a robust method to obtain defendable data on wildlife mortality. In: van der Ree R, Smith DJ, Grilo C (eds) Handbook of Road Ecology. Wiley-Blackwell, New York.

Gunson K, Teixeira FZ. 2015. Road-wildlife mitigation planning can be improved by identifying the patterns and processes associated. In: van der Ree R, Smith DJ, Grilo C (eds.). Handbook of Road Ecology. Wiley-Blackwell, New York.

Hamer AJ, Langton TE, Lesbarrères D. 2015. Making a safe leap forward: Mitigating road impacts on amphibians. In: van der Ree R, Smith DJ, Grilo C (eds) Handbook of Road Ecology. Wiley-Blackwell, New York.

Hastings H, Barr J, Bateman PW. 2019. Spatial and temporal patterns of reptile roadkill in the north-west Australian tropics. Pac Conserv Biol 25 (4): 370-376.

Hels T, Buchwald E. 2001. The effect of road kills on amphibian populations. Biol Conserv 99 (3): 331-340.

Hobday AJ. 2010. Nighttime driver detection distances for Tasmanian fauna: Informing speed limits to reduce roadkill. Wildl Res 37 (4): $265-$ 272.

Hughes WE, Reza Saremi A, Paniati JF. 1996. Vehicle-animal crashes: an increasing safety problem. ITE J 66: 24-29.

Husby M. 2017. Traffic influence on roadside bird abundance and behaviour. Acta Ornithol 52 (1): 93-103.

IUCN. 2020. IUCN Red List of Threatened Species. www.iucnredlist.org

Jeganathan P, Mudappa D, Kumar A, Raman TS. 2018. Seasonal variation in wildlife roadkills in plantations and tropical rainforest in the Anamalai Hills, Western Ghats, India. Curr Sci 114 (3): 619-626.

Laurance WF. 2015. Bad roads, good roads. In: van der Ree R, Smith DJ, Grilo C (eds) Handbook of Road Ecology. Wiley-Blackwell, New York.

Liu SL, Liu Q, Wang C, Yang JJ, Deng L. 2013. Effects of road construction on regional vegetation types. J Appl Ecol 24 (5): 1192 1198.
Legagneux P, Ducatez S. 2013. European birds adjust their flight initiation distance to road speed limits. Biol Lett 9 (5): 20130417.

Lynam AJ, Kreetiyutanont K, Mather R. 2001. Conservation status and distribution of the Indochinese tiger (Panthera tigris corbetti) and other large mammals in a forest complex in northeastern Thailand. Nat Hist Bull Siam Soc 49: 61-75.

Malo JE, Suárez F, Díez A. 2004. Can we mitigate animal-vehicle accidents using predictive models? J Appl Ecol 41 (4): 701-710.

Marsh DM, Page RB, Hanlon TJ, Corritone R, Little EC, Seifert DE, Cabe PR. 2008. Effects of roads on patterns of genetic differentiation in redbacked salamanders, Plethodon cinereus. Conserv Genet 9 (3): 603613.

Meunier FD, Verheyden C, Jouventin P. 2000. Use of roadsides by diurnal raptors in agricultural landscapes. Biol Conserv 92 (3): 291-298.

Montague L. 2009. East-West economic corridor (EWEC) strategy and action plan. https://mpra.ub.uni-muenchen.de/41147/

Office of National Park. 2017. Nam-Nao Nation Park. www.nps.dnp.go.th

Plante J, Jaeger JA, Desrochers A. 2019. How do landscape context and fences influence roadkill locations of small and medium-sized mammals? J Environ Manag 235: 511-520.

R Development Core Team. 2020. R: A language and environment for statistical computing. http://www.r-project.org/

Santos SM, Carvalho F, Mira A. 2011. How long do the dead survive on the road? Carcass persistence probability and implications for road-kill monitoring surveys. PLos ONE 6(9): e25383. DOI: 10.1371/journal.pone.0025383.

Selvan KM, Sridharan N, John S. 2012. Roadkill animals on national highways of Karnataka, India. J Ecol Nat Environ 4 (14): 363-365.

Shepard DB, Dreslik MJ, Jellen BC, Phillips CA. 2008. Reptile road mortality around an oasis in the Illinois corn desert with emphasis on the endangered eastern Massasauga. Copeia 2008 (2): 350-359.

Silva I, Crane M, Savini T. 2019. High roadkill rates in the Dong PhayayenKhao Yai World Heritage Site: Conservation implications of a rising threat to wildlife. Anim Conserv 10.1111/acv.12560

Smith MA, Green DM. 2005 Dispersal and the metapopulation paradigm in amphibian ecology and conservation: Are all amphibian populations metapopulations? Ecography 28: 110-128

Suwanwaree P, Aroon S. 2014. Vertebrates killed on the main road in Khao Yai National Park, Thailand. In: Tolvanen A, Hekkala AM (eds) The $9^{\text {th }}$ European Conference on Ecological Restoration, Oulu, 3-8 August 2014

Tongthiangdee P. 2003. Slope Failure along Long Lomsak-Chumpae Highway, Phetchabun Province, Thailand. [Dissertation]. Suranaree University of Technology, Nakhon Ratchasima.

van der Ree R, Jaeger JA, van der Grift EA, Clevenger AP. 2011. Effects of roads and traffic on wildlife populations and landscape function: Road ecology is moving toward larger scales. Ecol Soc 16 (1). DOI: 10.5751/ES-03982-160148.

van der Ree R, Smith DJ, Grilo C. 2015. Handbook of Road Ecology. Wiley-Blackwell, New York.

Venables WN, Ripley BD. 2002. Modern applied statistics with S. Springer, New York.

Wang Y, Piao ZJ, Guan L, Wang XY, Kong P, Chen J. 2013. Road mortalities of vertebrate species on Ring Changbai Mountain Scenic Highway, Jilin Province, China. North-Western J Zool 9 (2): 399-409.

Yue S, Bonebrake TC, Gibson L. 2019. Informing snake roadkill mitigation strategies in Taiwan using citizen science. J Wildl Manag 83 (1): 8088

Zhang W, Shu G, Li Y, Xiong S, Liang C, Li C. 2018. Daytime driving decreases amphibian roadkill. PeerJ 6: e5385. DOI: 10.7717/peerj.5385 6/18. 
Table S1. List of road killed species and number of carcass

\begin{tabular}{lllc}
\hline Common name & Scientific name & Family & No. of car \\
\hline Amphibians & & & \\
Stripe spadefoot frog & Calluella guttulata & Dicroglossidae & 1 \\
Rice frog & Fejervarya limnocharis & Dicroglossidae & 14 \\
Floating frog & Occidozyga lima & Dicroglossidae & 1 \\
Asian common toad & Duttaphrynus melanostictus & Bufonidae & 69 \\
Chinese edible frog & Hoplobatrachus rugulosus & Ranidae & 2 \\
Darksided Frog & Sylvirana nigrovittata & Ranidae & 102 \\
Koh Tao Island caecilian & Ichthyophis kohtaoensis & Caeciliidae & 7 \\
Malaysian painted frog & Kaloula pulcha & Microhylidae & 30 \\
Berdmore's chorus frog & Microhyla berdmorei & Microhylidae & 26 \\
Beautiful pygmy frog & Microhyla pulchra & Microhylidae & 1 \\
Northern treefrog & Polypedates mutus & Rhacophoridae & 75 \\
Black-webbed treefrog & Rhacophorus kio & Rhacophoridae & 3 \\
Unidentified & & & 247
\end{tabular}

\section{Reptiles}

Asian vine snake

Green cat snake

Spotted cat snake

Gray cat snake

Golden tree snake

Radiated ratsnake

Painted bronzeback

Bronzeback sp.

Common bridle snake

Malayan ringneck

Laotian wolf snake

White-banded wolf snake

Deuve's kukri snake

Banded kukri snake

Kukri Snake sp.

Red bamboo rat snake

Keeled slug-eating snake

Mountain slug snake

Common mock viper

Chinese ratsnake

Rat Snakes sp.

Red-necked keelback

Common collared snake

Malayan krait

Banded krait

Speckled coral snake

King cobra

MacClelland's coral snake

Burmese python

Pope's pit viper

White-lipped pit viper

Pit viper sp.

Diard's blind snake

Emma Gray's forest lizard

Blue-crested lizard

Oriental garden lizard

Bronze grass skink

Ahaetulla prasina

Boiga cyanea

Boiga multomaculata

Boiga siamensis

Chrysopelea ornata

Coelognathus radiata

Dendrelaphis pictus

Dendrelaphis sp.

Dryocalamus davidsonii

Liopeltis tricolor

Lycodon laoensis

Lycodon subcinctus

Oligodon deuvei

Oligodon fasciolatus

Oligodon sp.

Oreocryptophis porphyraceus

Pareas carinatus

Pareas margaritophorus

Psammodynastes pulverulentus

Ptyas korros

Ptyas sp.

Rhabdophis subminiatus

Sibynophis collaris

Bungarus candidus

Bungarus fasciatus

Calliophis maculiceps

Ophiophagus hannah

Sinomicrurus macclellandi

Python bivittatus

Trimeresurus popeiorum

Trimeresurus albolabris

Trimeresurus sp.

Argyrophis diardi

Calotes emma

Calotes mystaceus

Calotes versicolor

Eutropis macularia

Cyrtodactylus angularis

Gekko gecko

Varanus bengalensis

Heosemys spinosa
Colubridae 9

Colubridae 12

Colubridae 4

Colubridae 3

Colubridae 8

Colubridae 13

Colubridae 5

Colubridae 11

Colubridae 3

Colubridae 2

Colubridae 5

Colubridae 2

Colubridae 1

Colubridae 1

Colubridae 6

Colubridae 2

Colubridae 31

Colubridae $\quad 17$

Colubridae 5

Colubridae 19

Colubridae 4

Colubridae 5

Colubridae 9

Elapidae 3

Elapidae 1

Elapidae 1

Elapidae 1

Elapidae 1

Pythonidae 1

Viperidae 7

Viperidae 12

Viperidae 26

Typhlopidae 1

Agamidae $\quad 88$

Agamidae $\quad 10$

Agamidae 45

Scincidae 3

Gekkonidae 4

Gekkonidae 25

Varanidae 6

Geoemydidae 1 


\begin{tabular}{|c|c|c|c|}
\hline \multicolumn{4}{|l|}{ Birds } \\
\hline Crested goshawk & Accipiter trivirgatus & Accipitridae & 2 \\
\hline Bulbul sp. & Alophoixus sp. & Pycnonotidae & 1 \\
\hline Sooty-headed bulbul & Pycnonotus aurigaster & Pycnonotidae & 1 \\
\hline Stripe-throated bulbul & Pycnonotus finlaysoni & Pycnonotidae & 3 \\
\hline Black-crested bulbul & Pycnonotus flaviventris & Pycnonotidae & 1 \\
\hline Babblers sp. & Pellorneum sp. & Pellorneidae & 1 \\
\hline Largetailed nightjar & Caprimulgus macrurus & Caprimulgidae & 1 \\
\hline Lesser coucal & Centropus bengalensis & Cuculidae & 1 \\
\hline Greater coucal & Centropus sinensis & Cuculidae & 2 \\
\hline Greenbilled malkoha & Phaenicophaeus tristis & Cuculidae & 1 \\
\hline Yellow-bellied sunbird & Cinnyris jugularis & Nectariniidae & 2 \\
\hline White-rumped shama & Copsychus malabaricus & Muscicapidae & 2 \\
\hline Jungle crow & Corvus macrorhynchos & Corvidae & 1 \\
\hline Drongo sp. & Dicrurus sp. & Dicruridae & 1 \\
\hline Red Junglefowl & Gallus gallus & Phasianidae & 2 \\
\hline Asian barred owlet & Glaucidium cuculoides & Strigidae & 2 \\
\hline Brown Hawk-owl & Ninox scutulata & Strigidae & 1 \\
\hline Collared scops owl & Otus lempiji & Strigidae & 6 \\
\hline Spotted wood owl & Strix seloputo & Strigidae & 1 \\
\hline Black-naped monarch & Hypoyhymis azurea & Monarchidae & 2 \\
\hline White-rumped munia & Lonchura striata & Estrildidae & 1 \\
\hline Dark-necked tailorbird & Orthotomus atrogularis & Cisticolidae & 3 \\
\hline Common tailorbird & Orthotomus sutorius & Cisticolidae & 1 \\
\hline Plain Prinia & Prinia inornata & Cisticolidae & 1 \\
\hline Munia sp. & Phylloscopus sp. & Phylloscopidae & 4 \\
\hline Blue pitta & Pitta cyanea & Pittidae & 1 \\
\hline Blue-winged pitta & Pitta moluccensis & Pittidae & 1 \\
\hline Common bustard-quail & Turnix suscitator & Turnicidae & 1 \\
\hline Unidentified & & & 34 \\
\hline \multicolumn{4}{|l|}{ Mammals } \\
\hline Variable squirrel & Callosciurus finlaysonii & Sciuridae & 1 \\
\hline Indochinese ground squirrel & Menetes berdmorei & Sciuridae & 1 \\
\hline Spiny backed Rat & Maxomys surifer & Muridae & 1 \\
\hline Leopard cat & Prionailurus bengalensis & Felidae & 1 \\
\hline Roof rat & Rattus rattus & Muridae & 4 \\
\hline Northern Treeshrew & Tupaia belangeri & Tupaiidae & 4 \\
\hline Unidentified & & & 178 \\
\hline
\end{tabular}

